\title{
Выбор криопротектора
} для получения лиофилизированной
липосомальной лекарственной формы
производного индолокарбазола ЛХС-1269

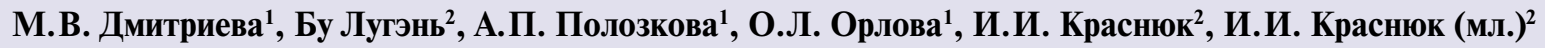 \\ ${ }^{\prime}$ ФГБУ «Национальный медицинский исследовательский центр онкологии им. Н. Н. Блохина» Минздрава России; \\ Россия, 115478 Москва, Каширское шоссе, 24; \\ ${ }^{2}$ ФАОУ ВО Первый Московский государственный медицинский университет им. И. М. Сеченова Минздрава России \\ (Сеченовский Университет); Россия, 119991 Москва, ул. Трубеикая, 8, стр. 2
}

К о н та к ты : Мария Вячеславовна Дмитриева dmitrieva.m@ronc.ru

\begin{abstract}
Введение. Одной из ключевых задач при сублимационном высушивании лекарственного препарата является выбор оптимального криопротектора (КП), обеспечивающего получение качественного лиофилизированного продукта.

Цель исследования. Выбор КП и его концентрации для получения лиофилизата липосомальной лекарственной формы производного индолокарбазола ЛХС-1269.

Материалы и методы. Субстанция ЛХС-1269 299 \% (ФГБУ «Национальный медицинский исследовательский центр онкологии им. H.Н. Блохина» Минздрава России), яичный фосфатидилхолин E PC S (Lipoid, Германия), холестерин $\geq 99$ \% (Sigma-Aldrich, Япония), полиэтиленгликоль-2000-дистеароилфосфатидилэтаноламин (Lipoid, Германия), манноза-D (+) 99 \% (Kaden, Германия), сахароза ЧДА («Химмед», Россия), трегалозы дигидрат ОСЧ («Химмед», Россия). Для получения липосом ЛХС-1269 использовали метод Бенгхема в модификации для гидрофобных субстанций с последующей экструзией дисперсии многослойных фосфолипидных везикул. Готовую липосомальную дисперсию дозировали во флаконы по 6 мл и лиофилизировали в камере сублимационной установки с использованием режима «ступенчатого» замораживания. Липосомы ЛХС-1269 анализировали до и после сублимационного высушивания с применением методов лазерной спектроскопии рассеяния и определения электрофоретической подвижности частиц.

Результаты. Для предотвращения разрушения липосом ЛХС-1269 в процессе лиофилизации исследовали вещества из класса углеводов: маннозу, сахарозу и трегалозу в 2 концентрациях. В ходе сравнительной оценки полученных лиофилизатов по показателям качества - внешний вид, регидратируемость, размер и дзета-потенциал липосом до и после сублимации - установлено, что оптимальными криопротективными свойствами обладает сахароза, вводимая в состав липосомальной лекарственной формы лХС-1269 в молярном соотношении сахароза/яичный фосфатидилхолин 5:1.

Заключение. В результате проведенного исследования выбран оптимальный КП и его концентрация, обеспечивающие получение качественного лиофилизата липосомальной композиции производного индолокарбазола ЛХС-1269.
\end{abstract}

Ключевые слова: лиофилизация, криопротектор, липосомы, яичный фосфатидилхолин, ЛХС-1269

Для цитирования: Дмитриева М.В., Лугэнь Бу, Полозкова А.П. и др. Выбор криопротектора для получения лиофилизированной липосомальной лекарственной формы производного индолокарбазола лХС-1269. Российский биотерапевтический журнал 2021;20(1):74-9.

\section{Selection of a cryoprotector for production a lyophilized liposomal dosage form of the indolocarbazole derivative LHS-1269}

Maria V. Dmitrieva', Bu Lugen ${ }^{2}$, Alevtina P. Polozkova', Olga L. Orlova', Ivan I. Krasnyuk ${ }^{2}$, Ivan I. Krasnyuk (Jr.) ${ }^{2}$

${ }^{l}$ N.N. Blokhin National Medical Research Center of Oncology of the Ministry of Health of the Russian Federation;

24 Kashirskoe Shosse, Moscow 115478, Russia;

${ }^{2}$ I.M. Sechenov First Moscow State Medical University, Ministry of Health of Russia; Build 2, 8 Trubetskaya St., Moscow 119991, Russia 
Cont a c t s: $\quad$ Maria Vyacheslavovna Dmitrieva dmitrieva.m@ronc.ru

Introduction. One of the key tasks in freeze-drying of drug is to choose the optimal cryoprotector that provides a high-quality lyophilized product.

The aim of research. Selection of cryoprotectant and its concentration for the preparation of lyophilizate of the liposomal dosage form of the indolocarbazole derivative LHS-1269.

Materials and methods. Substance LHS-1269 $\geq 99 \%$ (N.N. Blokhin National Medical Research Center of Oncology), egg phosphatidylcholine E PC S (Lipoid, Germany), cholesterol $\geq 99 \%$ (Sigma-Aldrich, Japan), polyethylene glycol-2000-distearoyl phosphatidylethanolamine (Lipoid, Germany), mannose-d (+) $99 \%$ (Kaden, Germany), sucrose (Himmed, Russia), trehalose dihydrate (Himmed, Russia). To obtain LHS-1269 liposomes, the Bangham method was used in modification for hydrophobic substances with subsequent extrusion of the dispersion of multilayer phospholipid vesicles. The prepared liposomal dispersion was dosed into vials of $6 \mathrm{ml}$ and lyophilized in the freeze-drying chamber using the «step-by-step» freezing mode. LHS-1269 liposomes were analyzed before and after freeze-drying using laser scattering spectroscopy and determination of the electrophoretic mobility of particles. Results. To prevent the destruction of LHS-1269 liposomes during lyophilization, substances from the carbohydrates class - mannose, sucrose and trehalose - were studied in two concentrations. In the course of comparative evaluation of the obtained lyophilizates in terms of quality, appearance, rehydration, size and zeta potential of liposomes before and after sublimation, it was found that sucrose introduced into the liposomal dosage form LHS-1269 in the molar ratio sucrose/egg phosphatidylcholine 5:1 has optimal cryoprotective properties.

Conclusion. As a result of the study, the optimal cryoprotector and its concentration were selected, which ensure the production of high-quality lyophilizate of the liposomal composition of the indolocarbazole derivative LHS-1269.

Key words: lyophilization, cryoprotector, liposomes, egg phosphatidylcholine, LHS-1269

For citation: Dmitrieva M.V., Lugen Bu, Polozkova A.P. et al. Selection of a cryoprotector for production a lyophilized liposomal dosage form of the indolocarbazole derivative LHS-1269. Rossiyskiy bioterapevticheskiy zhurnal = Russian Journal of Biotherapy 2021;20(1):74-9. (In Russ.).

\section{Введение}

За несколько десятков лет использования сублимационная сушка превратилась из лабораторной технологии в устоявшийся метод консервации широкого спектра фармацевтических продуктов. В течение этого периода были разработаны фундаментальные концепции, касающиеся разработки рецептур и процессов лиофилизации [1].

Технология процесса лиофилизации применяется прежде всего к лекарственным препаратам, которые нестабильны в водных растворах при комнатной температуре, для обеспечения более длительного срока хранения [2]. Липосомальная форма лекарственного вещества представляет собой гетерогенную дисперсную систему, где в качестве жидкой дисперсионной среды выступает вода, а дисперсной фазы собственно липосомы, сферические везикулы субмикронного диаметра, содержащие 1 или несколько биосовместимых липидных бислоев с водным ядром. Такие водные дисперсии обладают физической и химической нестабильностью, характеризующейся процессами окисления и гидролиза липосомальных липидов, в особенности ненасыщенных фосфолипидов, агрегацией или слиянием липосом. Данная проблема ограничивает широкое использование липосомальных препаратов и часто приводит к сокращению срока годности продукта [3]. Перевод посредством сублимационной сушки жидких липосомальных препаратов в безводную форму, в которой менее вероятна химическая деградация липидных компонентов, по- зволяет повысить стабильность при хранении и обеспечивает увеличение срока годности соответствующих фармацевтических продуктов при сохранении их терапевтической эффективности. Поскольку липосомы рассматриваются как упрощенная модель клеточной мембраны, для их лиофилизации используют те же методические подходы, которые применяются для биологических клеточных объектов [4].

Известно, что лиофилизация изменяет физическую структуру липосом. При замораживании липидные бислои могут разрываться в процессе образования кристаллов льда из водных фаз как внутри, так и снаружи везикул. Кроме того, во время сушки липосомы могут агрегировать или сливаться с образованием более крупных липидных частиц, вызывая утечку лекарственного вещества. Во время регидратации целостность липидного бислоя также может быть нарушена из-за фазовых переходов липидов [2]. Для предотвращения данных процессов и стабилизации липосомальной структуры в состав дисперсии вводят специальные вспомогательные вещества криопротекторы (КП).

Криопротекторы играют важную роль в защите структурной целостности липосом во время сублимационной сушки и последующего хранения. Несмотря на то что в технологии лиофилизации в качестве КП могут быть использованы соединения различных химических классов - спирты, альдегиды, амины, аминокислоты и их амиды, оксиды, полимеры и др. $[5,6]$, для сублимационного высушивания липосом 
в основном применяют углеводы - моно- и дисахариды $[7,8]$. После добавления в дисперсные липосомные системы молекулы сахара образуют водородные связи с фосфолипидами. Таким образом, температура фазового перехода кристаллического геля в жидкость уменьшается из-за менее плотно упакованных фосфолипидов. Это позволяет липосомальной мембране сохранять единую фазу во время процессов сушки и регидратации, предотвращая структурные переходы и утечку лекарственного вешества [2].

В лаборатории разработки лекарственных форм ФГБУ «Национальный медицинский исследовательский центр онкологии им. Н.Н. Блохина» Минздрава России разработана липосомальная лекарственная форма гидрофобного производного индолокарбазола ЛХС-1269 на основе ненасыщенного яичного фосфатидилхолина (ЯФХ) [9]. В связи с низкой стабильностью водной дисперсии липосом индолокарбазола предложено ее сублимационное высушивание.

Цель исследования - выбор КП и его концентрации для получения лиофилизата липосомальной лекарственной формы производного индолокарбазола ЛХС-1269.

\section{Материалы и методы}

Материалы и реактивы: субстанция ЛХС-1269 $\geq 99 \%$ (ФГБУ «Национальный медицинский исследовательский центр онкологии им. Н.Н. Блохина» Минздрава России), ЯФХ Е PC S (Lipoid, Германия), холестерин $\geq 99 \%$ (Sigma-Aldrich, Япония), полиэтиленгликоль-2000-дистеароилфосфатидилэтаноламина (Lipoid, Германия), манноза-D (+) 99 \% (Kaden, Германия), сахароза ЧДА («Химмед», Россия), трегалозы дигидрат ОСЧ («Химмед», Россия); хлороформ ХЧ, стабилизированный этанолом («Химмед», Россия); ацетон ЧДА («Химмед», Россия), вода для инъекций ФС. 2.2.0019.18; нейлоновые мембранные фильтры Pall N66 диаметром 47 мм с размером пор 1,2; 0,45 и 0,22 мкм (ООО «Палл Евразия», Россия).

Оборудование: весы электронные DL-120 (A\&D Co., LTD, Япония), весы аналитические Sartorius 2405 (Sartorius AG, Германия), испаритель роторный Неіdolph Hei-VAP Advantage с отгонной колбой на 2 л (Heidolph, Германия), экструдер Lipex $^{\mathrm{TM}}$ на 100 мл (Northern Lipids, Inc., Канада), ультразвуковая ванна Transsonic T310 (Elma, Германия), спектрофотометр Cary 100 (Agilent Technologies, Австралия), дзетасайзер Nanoseries Nano-ZS 3600 (Malvern, Великобритания), установка сублимационной сушки Edwards Minifast DO.2 (Ero Electronic S.p.A., Италия).

Методы. Получение липосом с ЛХС-1269. Липосомы получали по методу Бэнгхема в модификации для гидрофобных субстанций с последующей экструзией дисперсии многослойных фосфолипидных везикул ЛХС-1269. Более подробное описание метода получения липосом ЛХС-1269 представлено в работе Б. Лугэнь и соавт. [9].

Лиофилизация липосом с ЛХС-1269. К липосомальной дисперсии после экструзии добавляли навеску исследуемого КП, перемешивали до полного растворения и проводили стерилизующую фильтрацию через нейлоновые мембраны с размером пор 0,22 мкм. Полученную дисперсию разливали во флаконы по 6 мл и помещали в камеру сублимационной сушки при комнатной температуре $+20 \ldots+25^{\circ} \mathrm{C}$. Препарат замораживали, используя «ступенчатый» подход к снижению температуры: от комнатной температуры до $-5^{\circ} \mathrm{C}$ с выдерживанием при данной температуре в течение 30 мин для равномерного охлаждения продукта и далее от -5 до $-40{ }^{\circ} \mathrm{C}$ со скоростью $-10{ }^{\circ} \mathrm{C} / 4$. После достижения и уравновешивания минимальной температуры продукта $\left(-40{ }^{\circ} \mathrm{C}\right)$ флаконы с препаратом выдерживали в течение 3 ч и начинали откачку воздуха из камеры сублимационной установки. После включения вакуумного насоса и выравнивания вакуума (около 3 ч) осуществляли нагрев полок до температуры $-25^{\circ} \mathrm{C}$ со скоростью $+2,5^{\circ} \mathrm{C} / 4$ и выдерживание полок на температуре $-25^{\circ} \mathrm{C}$ в течение 2,5 ч, нагрев полок до температуры $-5^{\circ} \mathrm{C}$ со скоростью $1{ }^{\circ} \mathrm{C} /$ ч и нагрев полок до комнатной температуры $+20 \ldots+22^{\circ} \mathrm{C}$ со скоростью $+5^{\circ} \mathrm{C} /$ ч. Препарат досушивали для удаления остаточной влаги около 3 ч по критерию неизменности остаточного давления паров в сублимационной камере.

Определение среднего диаметра и дзета-потенци-

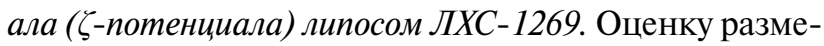
ра липосом ЛХС-1269 до и после лиофилизации проводили методом корреляционной спектроскопии

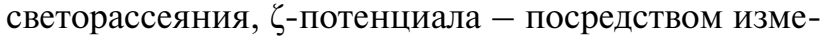
рения электрофоретической подвижности везикул. Для этого 100 мкл исследуемого образца свежеприготовленной или полученной после редиспергирования липосомальной дисперсии помещали в мерную колбу вместимостью 100 мл и доводили водой до метки. 1 мл полученного образца вносили в полистирольную кювету, которую помещали в ячейку дзетасайзера и проводили измерение показателей.

\section{Результаты}

Одной из задач разработки лиофилизированной формы любого фармацевтического продукта является выбор КП, который бы обеспечивал получение качественного лиофилизата в виде сухой пористой массы, способной к регидратации с образованием исходной гомогенной дисперсии с оптимальными физико-химическими характеристиками.

При проведении эксперимента по выбору оптимального КП для получения лиофилизата липосом ЛХС-1269 исследовали 3 наиболее широко используемых углевода - маннозу, сахарозу и трегалозу. 
Значения размера и Ђ-потенциала липосом ЛХС-1269 до лиофилизации с различными криопротекторами

Values of the size and $\zeta$-potential of LHS-1269 liposomes before lyophilization with various cryoprotectors

\begin{tabular}{|c|c|c|c|}
\hline $\begin{array}{l}\text { Криопротектор } \\
\text { Cryoprotector }\end{array}$ & $\begin{array}{c}\text { Молярное соотношение криопро- } \\
\text { тектор/ЯФХ } \\
\text { Molar ratio Cryoprotector/ EPC }\end{array}$ & $\begin{array}{l}\text { Средний размер } \\
\text { липосом, нм } \\
\text { The average size } \\
\text { of the liposomes, nm }\end{array}$ & $\begin{array}{c}\text { Среднее значение } \zeta \text {-потенциала } \\
\text { липосом, мB } \\
\text { The average value of } \zeta \text {-potential } \\
\text { of liposomes, mV }\end{array}$ \\
\hline $\begin{array}{l}\text { Контроль } \\
\text { Control }\end{array}$ & - & 169 & $-22,3$ \\
\hline \multirow{2}{*}{$\begin{array}{l}\text { Манноза } \\
\text { Mannose }\end{array}$} & $8: 1$ & 166 & $-16,4$ \\
\hline & $10: 1$ & 155 & $-24,6$ \\
\hline \multirow{2}{*}{$\begin{array}{l}\text { Сахароза } \\
\text { Sucrose }\end{array}$} & $4: 1$ & 146 & $-23,2$ \\
\hline & $5: 1$ & 146 & $-25,5$ \\
\hline \multirow{2}{*}{$\begin{array}{l}\text { Трегалоза } \\
\text { Trehalose }\end{array}$} & $4: 1$ & 153 & $-22,3$ \\
\hline & $5: 1$ & 155 & $-24,2$ \\
\hline
\end{tabular}

Примечание. ЯФХ-яичный фосфатидилхолин.

Note. EPC - Egg phosphatidylcholine.

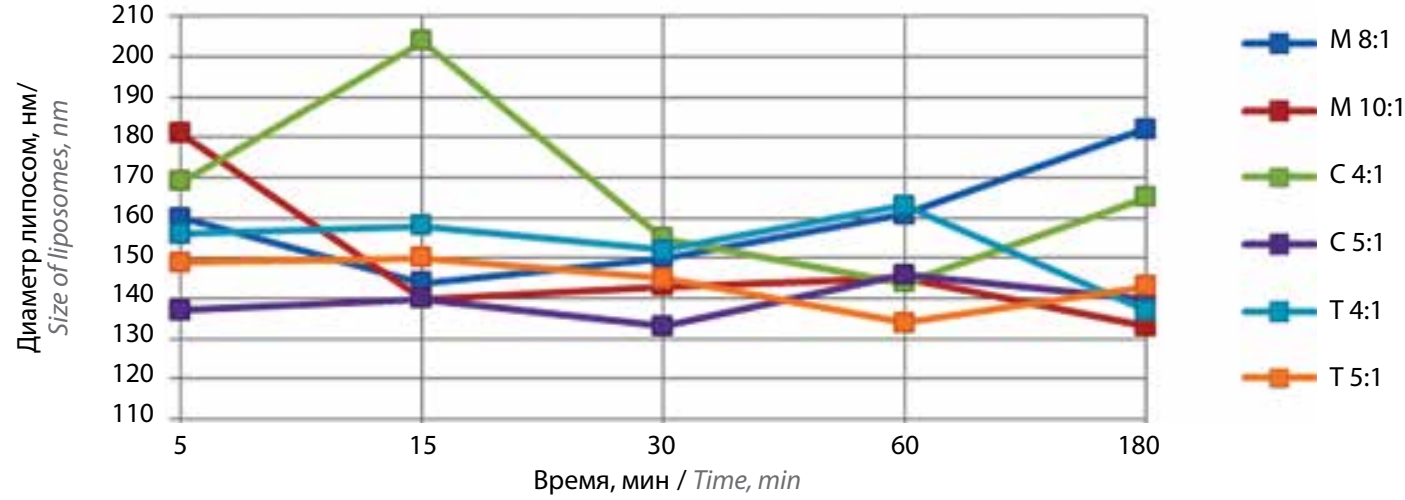

Рис. 1. Среднее значение размера липосом ЛХС-1269 через 5, 15, 30, 60 и 180 мин после редиспергирования в воде для инбекций лиофилизатов, содержащих исследуемые криопротекторы. $M$ - манноза, $C$ - сахароза, $T$ - трегалоза

Fig. 1. The average value of the liposome size of LHS-1269 at 5, 15, 30, 60 and 180 min after redispergation in water for injection of lyophilizates containing the studied cryoprotectors. $M$ - mannose, $C$ - sucrose, $T$ - trehalose

Поскольку КП обеспечивает защитное действие именно в отношении липидного бислоя липосомы за счет связывания с фосфолипидами, одним из условий успешной лиофилизации является соблюдение молярного соотношения КП/фосфолипид. Маннозу вводили в липосомальную дисперсию ЛХС-1269 в молярных соотношениях КП/ЯФХ 8:1 и 10:1, дисахара 4:1 и 5:1, что обусловлено различием в химическом строении и молекулярной массе данных соединений. В качестве контроля использовали липосомальную дисперсию, не содержащую КП. Сравнительную оценку качества полученных лиофилизатов проводили по таким показателям, как описание, регидратируемость/редиспергируемость, средний размер и 丂-потенциал липосом до сублимационного высушивания (см. таблицу) и после регидратации в воде через определенные промежутки времени - 5, 15, 30, 60 и 180 мин.
Все образцы лиофилизатов представляли собой сухую пористую массу в виде таблетки. При редиспергировании контрольного лиофилизата в воде для инъекций образовалась неоднородная вязкая масса с 2 фракциями везикул, средний размер которых в течение всего исследуемого периода времени варьировал в диапазоне 276-833 нм для преобладающей фракции (90 \% и более) и 21-56 нм для меньшей фракции, а значение $\zeta$-потенциала находилось в пределах от $-26,6$ до $-28,9$ мВ.

При сравнении образцов лиофилизатов с маннозой, сахарозой и трегалозой установлено, что химическая природа углевода играет лишь незначительную роль в формировании лиофилизата, поскольку все указанные сахара проявили требуемые криопротекторные свойства при лиофилизации исследуемых липосом. Практически во всех 6 образцах после регидратации отмечалось уменьшение или незначительное 


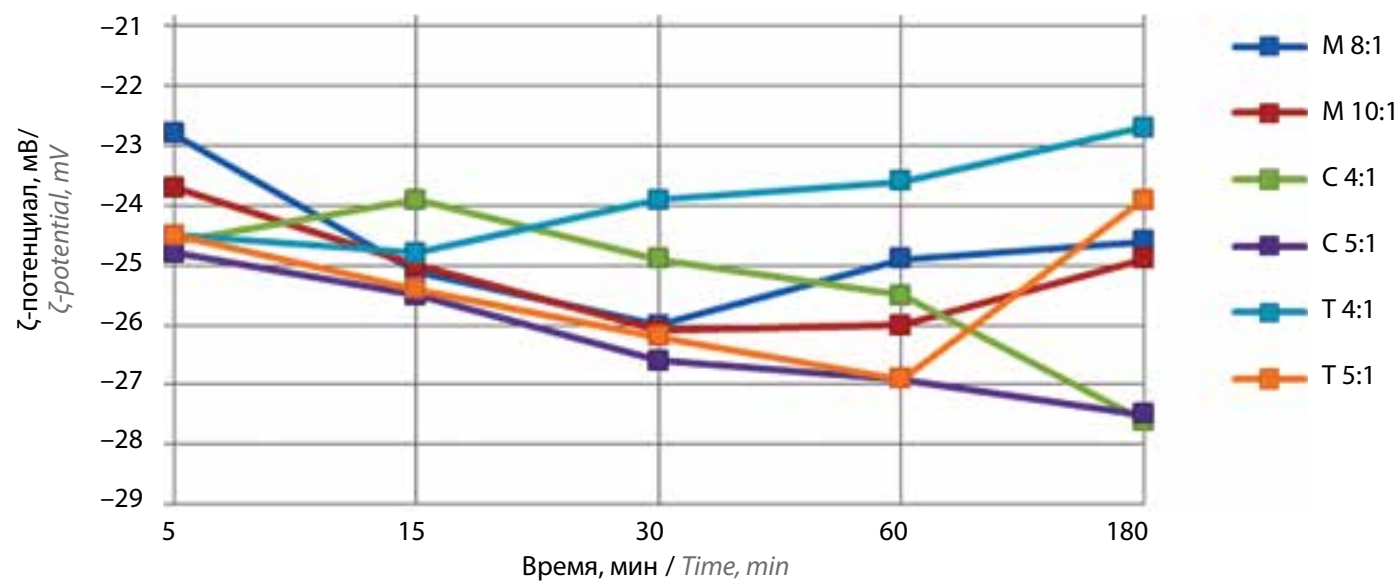

Рис. 2. Среднее значение Г-потенциала липосом ЛХС-1269 через 5, 15, 30, 60 и 180 мин после редиспергирования в воде для инбекций лиофилизатов, содержащих исследуемые криопротекторы. $M$ - манноза, C- сахароза, $T$ - трегалоза

Fig. 2. Average value of the $\zeta$-potential of LHS-1269 liposomes at 5, 15, 30, 60 and 180 min after redispergation in water for injection of lyophilizates containing the studied cryoprotectors. $M$ - mannose, $C$ - sucrose, $T$ - trehalose

укрупнение среднего диаметра везикул и повышение

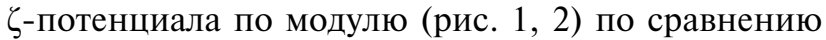
со значениями, полученными до лиофилизации. Исключение составил лиофилизат с сахарозой 4:1 - на протяжении исследуемого периода времени (180 мин) наблюдались значительные колебания размера везикул (см. рис. 1).

При редиспергировании образцов с маннозой 8:1 и трегалозой 4:1 получали неустойчивые во времени липосомальные дисперсии. Спустя 15-30 мин после добавления воды для инъекций фиксировали минимальные значения диаметра и 丂-потенциала везикул, однако затем наблюдали их укрупнение и снижение поверхностного заряда по модулю. Стабильность дисперсий удалось повысить при использовании КП в большей концентрации. На протяжении 3 ч после редиспергирования лиофилизатов отмечали сохранение среднего размера липосом, содержащих маннозу 10:1, сахарозу 5:1 и трегалозу 5:1 (см. рис. 1). Однако стойкое повышение уровня 丂-потенциала с $-24,8$ до $-27,5$ мВ в течение 180 мин наблюдали только для дисперсии, содержащей сахарозу в молярном соотношении КП/ЯФХ 5:1, что свидетельствует о ста- бильности липосомальной структуры и снижении риска слияния и/или агрегации везикул.

\section{Заключение}

Сохранение физической целостности липосомальной структуры в процессе сублимационного высушивания имеет первостепенное значение и может быть достигнуто путем включения в состав лекарственной формы специального эксципиента КП. При исследовании образцов лиофилизированных липосом ЛХС-1269 с маннозой, сахарозой и трегалозой в 2 молярных соотношениях КП/ЯФХ установлено, что на качество продукта в первую очередь влияет концентрация используемого углевода и лишь незначительно - его структура. В результате сравнительной оценки полученных лиофилизатов по показателям качества - описание внешнего вида, регидратируемость, размер и Ђ-потенциал липосом до и после сублимации, установлено, что оптимальными криопротективными свойствами обладает сахароза, вводимая в состав липосомальной лекарственной формы ЛХС-1269 в молярном соотношении сахароза/ЯФХ 5:1.

\section{$\begin{array}{lllllllllllllllllllll}\text { Л } & \text { U } & \text { T } & \text { E } & \text { P } & \text { A } & \text { T } & \text { V } & \text { P } & \text { A } & \text { I } & \text { R } & \text { E } & \text { F } & \text { E } & \text { R } & \text { E } & N & \text { C } & \text { E } & S\end{array}$}

1. Kasper J.C., Winter G., Friess W. Recent advances and further challenges in lyophilization. Eur J Pharm Biopharm 2013;85(2):162-9.

DOI: 10.1016/j.ejpb.2013.05.019.

2. Wang Y., Grainger D.W. Lyophilized liposome-based parenteral drug development: reviewing complex product design strategies and current regulatory environments. Adv Drug Deliv Rev 2019;151-152:56-71.

DOI: $10.1016 /$ j.addr.2019.03.003.

3. Ghanbarzadeh S., Valizadeh H., ZakeriMilani P. The effects of lyophilization on the physico-chemical stability of sirolimus liposomes. Adv Pharm Bull
2013;3(1):25-9.

DOI: $10.5681 / \mathrm{apb} .2013 .005$.

4. Шанская А.И., Пучкова С.М., Хмылова Г.А., Недачина Н.А. Липосомальный препарат Липоферол для внутривенного введения с альфа-токоферолом. Актуальные вопросы трансфузиологии и клинической 
медицины 2015;1:156-8. [Shanskaya A.I., Puchkov S.M., Chmielova G.A., Neudachina N.A. Liposomal drug Lipoferum for intravenous administration with alpha-tocopherol Actualniye voprosi transfuziologii i klinicheskoy meditsini $=$ Topical issues of Transfusiology and clinical medicine 2015;1:156-8. (In Russ.)].

5. Костяев А.А., Утемов С.В., Андреев А.А. и др. Анналы криобиологии. Классификация криопротекторов и криоконсервантов для клеток крови и костного мозга. Вестник гематологии 2016;12(3):23-7. [Kostyaev A.A., Utemov S.V., Andreev A.A. et al. Annals of Cryobiology. Classification of cryoprotectors and cryopreservants for blood cells and bone marrow. Vestnik gematologii $=$ Bulletin of Hematology 2016;12(3):23-7. (In Russ.)].

6. Izutsu K.I. Applications of freezing and freeze-drying in pharmaceutical formulations. Adv Exp Med Biol 2018;1081:371-83.

DOI: $10.1007 / 978-981-13-1244-120$.

7. Guimarães D., Noro J., Silva C. et al. Protective effect of saccharides on freeze-dried liposomes encapsulating drugs. Front Bioeng Biotechnol 2019;7:424. DOI: 10.3389/fbioe.2019.00424.

8. Li J., Hu M., Xu H. et al. Influence of type and proportion of lyoprotectants on lyophilized ginsenoside $\operatorname{Rg} 3$ liposomes. J Pharm Pharmacol
2016:68(1):1-13. DOI: $10.1111 /$ jphp. 12489.

9. Лугэнь Б., Дмитриева М.В., Орлова О.Л. и др. Разработка состава липосомальной лекарственной формы гидрофобного производного индолокарбазола. Разработка и регистрация лекарственных средств 2020;9(3):21-6. DOI: 10.33380/2305-2066-2020-9-3-2126. [Lugen B., Dmitrieva M.V., Orlova O.L. et al. Development of a liposomal dosage form based on hydrophobic derivative of indolocarbazole. Razrabotka i registratsiya lekarstvennykh sredstv $=$ Drug development \& registration 2020;9(3):21-6. (In Russ.)].

\section{Вклад авторов}

М.В. Дмитриева, Бу Лугэнь: дизайн исследования, проведение экспериментов и анализ данных, написание текста статьи и подготовка к публикации;

А.П. Полозкова, О.Л. Орлова: лиофилизация образцов, редактирование статьи;

И.И. Краснюк, И.И. Краснюк (мл.): дизайн исследования, перевод, проверка конечной версии рукописи.

Authors contributions

M.V. Dmitrieva, Bu Lugen: research design, carrying experiments and data analysis, writing the text of the article and preparing for publication;

A.P. Polozkova, O.L. Orlova: lyophilization of samples, editing of the article;

I.I. Krasnyuk, I.I. Krasnyuk (jr.): research design, translation, verification of the final version of the manuscript.

ORCID авторов / ORCID of authors

М.В. Дмитриева / M.V. Dmitrieva: https://orcid.org/0000-0001-6740-5692

Бу Лугэнь / Bu Lugen: https://orcid.org/0000-0002-7740-5562

О.Л. Орлова / O.L. Orlova: https://orcid.org/0000-0002-4558-0083

И.И. Краснюк / І.І. Krasnyuk: https://orcid.org/0000-0003-4382-7377

И.И. Краснюк (мл.) / I.I. Krasnyuk (Jr.): https://orcid.org/0000-0001-8557-8829

Конфликт интересов. Авторы заявляют об отсутствии конфликта интересов. Conflict of interest. The authors declare no conflict of interest.

Финансирование. Исследование проведено без спонсорской поддержки.

Financing. The study was performed without external funding. 